\title{
A DESCOLONIZAÇÃO EPISTEMOLÓGICA PELA MORTE AOS OLHOS DA INFÂNCIA - ANÁLISES DA LITERATURA DE MIA COUTO
}

\author{
THE EPISTEMOLOGICAL DECOLONIZATION \\ THROUGH THE DEATH BY EYE OF CHILDHOOD - \\ ANALYSIS OF MIA COUTO LITERATURE
}

Camila Lima Sabino ${ }^{1}$

\section{RESUMO}

Este trabalho consiste em uma análise comparativa das obras $O$ beijo da palavrinha e A chuva pasmada do escritor moçambicano Mia Couto, obras endereçadas ao público infantil e juvenil. O objetivo é investigar consonâncias e divergências dos tratamentos literários dados às temáticas da morte e da infância, e analisar, a partir desses tratamentos, processos histórico-culturais que permitem equacionar as heranças coloniais no contexto social e político de Moçambique. O protagonismo infantil e as representações literárias das famílias frente à morte permitem refletir sobre o lugar da infância como lugar de trânsito e de produção de cultura o que, em consequência, desloca o papel do adulto e das instituições sociais e permite pensar na multiplicidade sócio-cultural constitutiva das identidades individuais e sociais. Buscamos, com tais deslocamentos observados nas propostas literárias concernentes ao corpus deste trabalho, defender a necessidade de aprimorar o processo de descolonização política e epistemológica dos espaços sociais marginalizados, compreendendo a modernidade e o sistema-mundo capitalista como a dupla face da colonialidade.

PALAVRAS-CHAVE: morte; infância; descolonização epistemológica. 


\section{ABSTRACT}

This article consist a comparative analysis of "O beijo da palavrinha" and "A chuva pasmada", both works from the Mozambican writer Mia Couto, addressed to young people and children. The objective is to investigate the consonance and the differences of literary treatments given to the themes of death and childhood, as also to analyze, from these treatments, the historical and cultural processes that allow to equal the colonial heritage in the social and political context in Moçambique. The children's role and the literary representations of families facing death allows us to reflect about childhood as a place of transit and cultural production; that consequently shifts the adult role and social institutions and to also suggest the constitutive socio multiplicity of an individual cultural and social identities. By such displacements, we aim to observe literary proposals regarding the corpus of those works, sustaining the need to improve the process of political and epistemological decolonization of marginalized social spaces, including the modernity and the capitalist world-system as the double face of colonialism.

KEYWORDS: death; childhood; decolonization epistemological.

A presente pesquisa objetiva equacionar as heranças coloniais nas obras O beijo da palavrinha (2006) e A chuva pasmada (2004) do moçambicano Mia Couto. E, à medida que escolhas epistêmicas alternativas à dominante reverberam em tais obras, torna-se possível desenvolver reflexões críticas acerca dessas heranças. Ao aproximar infância e morte, em seu projeto estético, o autor, cujas obras compõem o objeto de estudo deste artigo, nos fornece material para engendrar um exercício de descolonização do olhar à luz do que afirma o argentino Walter Mignolo sobre a opção descolonial em seu artigo "Desobediência epistêmica: A opção descolonial e o significado de identidade em política”, publicado, em 2007, na Revista Gragoatá e, em 2008, no Caderno de Letras da UFF. Para Mignolo, a opção descolonial é uma estrada para a pluriversalidade como um projeto universal e tem como pilar a desobediência epistêmica, o que significa deixar a estrutura do pensamento controlado pela política e pela economia eurocêntricas.

Os tratamentos literários dados à morte e à infância nos objetos de estudo assumem posicionamentos contrários ao caráter homogeneizante da institucionalização da educação, que, no mais das vezes, se baseia na forma como a lógica ocidental influencia a sociedade, a cultura e a epistemologia desse país, que, no contraste geopolítico do mundo, assume a margem. Como lógica ocidental, compreendemos o processo da modernização como continuidade do sistema colonial que determinou a posição de Moçambique. Denunciamos, portanto, a necessidade do aprimoramento 
do exercício de descolonização, compreendendo que a independência de Moçambique não interrompeu o processo de construção cultural e epistemológico empreendido pelo sistema colonial.

Pensamos o papel de mediação e articulação do conhecimento de autores como Mia Couto junto aos mais novos, evidenciando o papel social da criança como produtora de culturas. As infâncias, tanto as representadas em personagens dos textos literários quanto as que compõem o público-leitor das obras, são deslocadas de sua condição por vezes inferiorizada em comparação com a dos adultos e, na maioria das vezes, separada da sociedade pelo fio da razão. Ou seja, a racionalidade louvada desde a modernidade com o iluminismo, opera um abismo entre o grupo que compõe o racional, o universal, o humano e os Outros, que são excluídos.

Dessa forma, assim como Hegel $^{2}$ chama a África de continente criança no século XIX e com essa assertiva se fundamentam as diretrizes civilizatórias e pedagogizantes dos povos africanos; os adultos, as instituições, a legislação dos países globalizados, em sua maioria, operam uma espécie de colonização da infância, uma vez que, ao não serem consideradas como produtoras de cultura e conhecimento, as crianças incorporam, sem o fomento do diálogo crítico, a formação padronizante do cidadão ocidental, patriarcal, capitalista, branco, europeu e cristão.

A morte vivenciada pelos personagens das obras de Mia Couto é colocada como um elemento de troca biossimbólica, para trazer um conceito de Muniz Sodré, sociólogo brasileiro, em seu livro A verdade seduzida (2005), com o qual junto de outros, empreenderemos as leituras das obras de Mia Couto. Sodré pensa a organização dos terreiros da Bahia fundados por concepções filosóficas norteadoras de uma cultura negra no contexto brasileiro. Sodré compreende que se trata de uma cultura reposta que dialoga com situações e contextos brasileiros ligados ao processo escravagista e ao sistema colonial. O sociólogo explica a aplicação de uma série de conceitos nos rituais negros, tais como segredo, luta, feitiço, as regras do jogo e o axé, como a força vital ligada ao movimento, único objetivo dos rituais. O sociólogo explica, inclusive, as diferenças entre trocas simbólicas e trocas não-simbólicas que nos leva a perceber o salto das relações vivenciadas em sociedades tradicionais versus as trocas na modernidade com o advento do capitalismo.

Em linhas gerais, Sodré explica que, na lógica do ritual negro, há sempre um segredo disjuntivo das ações do ritual; pois a iniciação é um processo de separação entre quem sabe e quem não sabe; o segredo, no entanto, é um conhecimento que não encerra um poder, porque as trocas são operadas pela ideia de dual, ou seja, o que um componente do elemento do grupo sabe, os outros sabem, em ausência. O saber positivo existe em função do negativo e, no positivo, o negativo existe. Assim, o que importa não é o desvendamento do mistério, mas a luta que o mesmo opera e essa luta ocorre em termos de troca simbólica. A saber, 
$\mathrm{Na}$ cultura negra, a troca não é dominada pela acumulação linear de um resto (o resto de uma diferença), porque é sempre simbólica e, portanto, reversível: a obrigação (de dar) e a reciprocidade (receber e restituir) são as regras básicas. É o grupo (concreto) e não o valor (abstrato) que detém as regras das trocas. E a troca simbólica não exclui nenhuma entidade: bichos, plantas, minerais, homens (vivos e mortos) participam ativamente, como parceiros legítimos de troca, nos ciclos vitais. (SODRÉ, 2005, p. 95)

Dispensando, portanto, a hipótese de que a verdade por trás do segredo seja a salvação ou o resultado do objetivo principal, no ritual negro, o segredo é mantido e gera o desafio para que a luta ocorra. O objetivo principal é o fim da imobilidade: a partir da provocação (do segredo), as reações dos que são implicados, nesse jogo, são o que gera o movimento. Segundo Sodré, "Na cultura negra, não existe nenhuma doutrina realista da morte, pois essa integra o princípio simbólico das trocas coletivas. Toda morte é biossimbólica" (SODRÉ, 2005, p. 95).

Outra obra que discute a morte pelo viés da troca simbólica é $A$ troca simbólica e a morte (1996) do francês Jean Baudrillard. Baudrillard potencializa a problemática da separação entre vida e morte, à luz dos objetivos da igreja cristã $\tilde{a}^{3}$, do poder do estado e da economia política do capital. A vida ganha, portanto, outro objetivo: manter-se separada da morte através do trabalho, da acumulação de capital, que significa acumulação do tempo. A morte separada da vida se transforma na morte diferida e a restituição, a troca biossimbólica, fica impossibilitada. A morte escondida do indivíduo, portanto, gera uma tensão latente e um lugar profundo de abstração e de medo.

Tanto em O beijo da palavrinha como em A chuva pasmada, a sequência narrativa angaria elementos para a vivência da morte como troca simbólica; os processos são gradativos, as situações em desequilíbrio são expostas e as soluções para as mesmas são engendradas coletivamente, ou seja, os componentes dos grupos vivenciam rituais de passagem que os tornam conscientes de seus papéis em processos de atribuição de sentido à morte, por exemplo, que também é um ritual de transformação.

Para apreender esse processo ritualístico, nos utilizamos da obra Cultura Tradicional Banto (1985) escrita pelo Padre Raul Ruiz de Asúa Altuna, obra que capta a realidade tradicional banto, e que problematiza tal realidade compreendo-a de forma múltipla e diversificada, tal qual afirma Altuna no prefácio: “Tentámos somente recolher dados etnológicos para conseguir uma visão de conjunto dos constitutivos mais fundamentais desta cultura e assim possibilitar a explicação e a compreensão das variadíssimas manifestações locais e particulares" (ALTUNA, 1974, p. 9).

No contexto ficcional, portanto, buscamos desvelar marcas dessa cultura tradicional como um passado coletivo já dinamizado nas vissicitudes dos grupos sociais contemporâneos, em que os efeitos do capitalismo 
como sistema histórico e cultural são percebidos em termos de miséria e pobreza. As famílias detêm o lugar da margem e fazem da resistência filosófica e cultural local, o instrumento de combate da sua subjugação.

O autor moçambicano, no corpus do trabalho, aborda a questão da morte como um elemento que excede à compreensão humana calcada nos padrões científicos, método que não apreende a relação entre vivos e mortos e as práticas de feitiçaria, para citar dois exemplos dentre muitos outros por serem ainda mapeados. Trata-se de percepções, conceitos, crenças inapreensíveis pelos instrumentos que a ciência disponibiliza e a regulação e gestão políticas acabam por desconsiderar, negligenciando assim modos de atribuição de sentidos à realidade e deslegitimando certas experiências humanas.

Pela exposição da lógica da existência de um invisível, espaço de incerteza, cujos efeitos na realidade são indiscutíveis, Mia Couto apresenta tratamentos culturais dados à morte com base em outra ordem de saberes e assim reclama a necessidade de reconhecimento da diversidade. Ao nomear e definir um saber local/próprio, uma comunidade desenvolve meios políticos para resistir em um cenário que, muitas vezes, a descaracteriza em função do processo homogeneizante da globalização. Nesse sentido, ao reorganizar a simbologia mítica no espaço literário, por vezes contando de outros modos narrativas mitológicas, o moçambicano aponta para as novas roupagens que assumem as lógicas estruturais de organização social das sociedades marginalizadas bem como suas novas formas de engendrar as relações de poder na realidade moderna.

É importante para o trabalho, portanto, o levantamento que faz a socióloga Maria Paula Meneses em artigo intitulado "Corpos de violência, linguagens de resistência: as complexas teias de conhecimento no Moçambique contemporâneo"(2010), do processo da autoconstrução da identidade europeia em detrimento das identidades dos povos não europeus. A Europa se assume como portadora de uma identidade superior em relação aos povos não europeus, a relação se estabelece, portanto, a partir do prisma monocultural da ciência moderna. Assim: "As fronteiras da civilização tornaram-se as margens de um sentido de ordem social europeia; consequentemente, os nativos tornaram-se a própria desordem, simbolizada pelo seu sofrimento moral, degradação física e mundo desordenado" (MENESES, 2010, p. 225-226).

É desta forma que, sem os parâmetros necessários para a compreensão dos outros saberes, a dimensão mágica do sistema político desses espaços regionais acaba sendo negligenciada pelos estudos históricos e filosóficos, mas não deixam de ser instrumentos de lideranças populares. Do mesmo modo, sem os parâmetros necessários para a apreensão da dimensão mágica da cultura moçambicana, quando entramos no imaginário ficcional de Mia Couto, o primeiro impulso interpretativo é o de tentar desvelar as situações "mágicas" que ocorrem na narrativa. Isso porque respon- 
demos à necessidade de conferir sentidos, sobretudo, racionais aos eventos, sejam estes da ordem do real ou do literário. No entanto, a partir de estudos como os de Muniz Sodré, encontramos outros modos de compreender as particularidades culturais e políticas subjacentes à concepção ficcional coutiana, para além da tentativa de esclarecer enigmas e dissolver problemas.

A obra artística de Mia Couto compõe um espaço de revisão e problematização do que é considerado tradicional em uma literatura forjada a partir de um sistema de pensamento constituído pela oralidade, refletindo as diversas formas de percepção de mundo existentes a partir deste tipo de linguagem, englobando ainda seu lugar de fala de fronteira, situado no tempo da modernidade. O universo simbólico de tradições, mitos e lendas são colocados em tensão com elementos da atualidade moderna, em que a pobreza e a miséria, muitas vezes, dão o tom das ações dos personagens e norteiam as resoluções dos conflitos narrativos.

Nesse sentido, adentremos no território ficcional dos personagens de $O$ beijo da palavrinha. Trata-se da estória de Maria Poeirinha, que vive em um lugar tão interior com sua família que o rio que por lá passava parecia não ter fim ou foz. A trama começa pela informação de que a menina nunca vira o mar. A personagem mostra-se, desde o início, ligada à ideia de transitoriedade, uma vez que a poeira é matéria que paira, no mais das vezes, no espaço intermediário entre a terra e o céu.

Zeca Zonzo é o único irmão de Poeirinha e é descrito como sem juízo. Caracterizado como aéreo, o personagem divide com a irmã a qualidade etérea, uma qualidade também ligada ao imaginário. Tal comportamento de Zeca inicialmente observado pelos adultos como resultante de uma loucura é justamente o lugar de resistência que engendra a resolução da problemática da trama, a saber: Maria Poeirinha fica doente e parece não saber morrer. Diante da falta de recursos, os adultos não podem ajudá-la, mas Zeca desenvolve um modo próprio para a questão, como será exposto mais adiante. Ambos os personagens, Zeca e Poeirinha, vivem de forma correspondente às suas realidades, compartilham pequenos sonhos, porque possuem uma realidade de miséria. Ou seja, a miséria compõe o pano de fundo da narrativa, o que nos permite deixar uma visão romântica em que as concepções culturais arcaicas existiriam sem ressalvas. Trata-se, porém, de saberes em tensão, os locais e os globais. Os irmãos assemelham-se, sobretudo, em relação ao fato de estarem pouco arraigados no plano físico: Poeirinha parece já estar desfalecida desde o início da trama e Zeca Zonzo parece ter uma leitura pouco definida do mundo que o cerca.

Nesse sentido, Poeirinha não só fala como sonha: "às vezes, sonhava que ela se convertia em rio e seguia com passo lento, como princesa de um distante livro, arrastando um manto feito de remoinhos, remendos e retalhos" (COUTO, 2006). Nessa dimensão onírica, podemos perceber o germe de sua transformação em água, e seu vestuário de princesa feito por um manto de remodelações propõe que Poeirinha antevê o fato de estar envolvida por múltiplos elementos costurados em tensão. 
É a chegada de Tio Jaime Litorânio que aprofunda a discussão e a percepção em torno da representação do mar. O mar é o elemento mágico que permitirá a conjugação do plano ordinário (da vida) com o extraordinário (da morte ou do outro lado da vida). A primeira informação exposta no livro é índice de que este contato com o mar é um marco definitivo para Poeirinha, como dito anteriormente, a personagem nunca havia visto o mar.

A surpresa de Litorânio é que seus familiares não conheciam o mar, porque, para esse personagem, o mar representava o infinito e, portanto, não conhecê-lo, simbolizava uma falta na vida dos familiares. É seu o seguinte pensamento: "Podia continuar pobre mas havia, do outro lado uma luz que fazia a espera valer a pena. Deste lado do mundo, faltava essa luz que nasce não do Sol mas das águas profundas" (COUTO, 2006). É interessante observar que uma vez que o mar é o lugar da morte enquanto transformação, é a sua escuridão que falta na vida dos familiares e não a luz do sol. Resgatando a divisão forjada entre vida e morte pela ideologia capitalista dominante da igreja e do estado ocidentais, com base no discurso teórico de Baudrillard; percebemos o mar como a presença pela ausência, na vida dos personagens, a partir dessa fala de Litorânio. Ou seja, o mar representa um elemento que deve ser restituído naquela realidade, assim como sua simbologia de transformação ligada à morte.

Portanto, é quando Maria Poeirinha fica muito doente, que o mar ocupa o espaço foco da narrativa, já que, segundo o Tio, sua única salvação seria encontrá-lo. A menina, no entanto, não dispõe de força suficiente para entrar efetivamente em contato com o mar e acaba fazendo-o de maneira imaginária. Zeca Zonzo, o personagem que parece estar mais aquém do paradigma da racionalidade, ou seja, um estonteado, imerso na fantasia, incapaz de se integrar enquanto sujeito, é quem a acolhe e auxilia em sua travessia. Os irmãos encontram-se, porque crianças, capazes de compartilhar de uma atitude mágica diante da vida e encarnar conscientemente a necessidade de considerar o saber mágico presente na cultura e na política daquela sociedade.

Zeca leva à irmã papel e caneta, no qual escreve a palavra MAR e constrói junto à Poeirinha essa forma fantasiosa de entrar em contato com o mar, e, consequentemente, com a morte. Ambos vão delineando juntos com os dedos a letra $\mathrm{M}$ no papel e descobrem o movimento ondulatório das vagas do oceano; depois é a letra A que representa uma gaivota pousada nela própria e por fim, a força está clara na letra $\mathrm{R}$ de rocha.

O movimento ondulatório pode ser lido como o movimento cíclico da vida, o transitório, o que nunca para; a gaivota simboliza o voo, a ida para o infinito do céu e a força parece ser essencial à Poeirinha, como se morrer demandasse um esforço, o de transmutar-se em outra natureza, entender-se como continuidade e, mesmo distante fisicamente da família, presente e infinita. A força da rocha é necessária, sobretudo, para os que 
ficam, para quem a ausência deve ser compreendida como uma oportunidade de vislumbrar o todo a que todos estão unidos e inseridos, através de um continuum de tempo e espaço que se sobreleva à vida ordinária. Maria Poeirinha e seu irmão Zeca Zonzo colocam em prática as regras de um ritual, através do qual Poeirinha é o elemento da realização de uma troca simbólica. Como o ritual não pode ser praticado individualmente, o irmão participa ativamente do momento de sua morte junto do Tio Jaime Litorânio, responsável por evocar a simbologia do mar.

Nesse momento, o Tio compreende a necessidade da fantasia como um saber através do qual o conflito da narrativa se desfaz, um saber que estava nele solapado, anteriormente. Junto ao leitor, a fantasia é também legitimada, pois Mia Couto desenvolve um texto que desenha a morte de Poeirinha: "do leito de Maria Poeirinha se ergueu a gaivota branca, como se fosse um lençol agitado pelo vento" (COUTO, 2006). No contexto moçambicano, tal fantasia se conjuga bem com a resolução mística que é dada ao evento da morte, vista como um fim somente por culturas que não compartilham de uma visão da vida entrelaçada com a morte, em que não há sentimento de perda ou medo do desconhecido. Nas culturas tradicionais africanas, a morte é uma passagem e, de outro modo, o ser morto continua vivo. É assim, portanto, que Zeca Zonzo apresenta a morte da irmã, terminando o livro dizendo que Poeirinha havia sido beijada pelo mar e afogada numa palavrinha.

O que podemos observar, de forma cotejada e transfigurada na sutileza da trajetória em direção à morte vivenciada por Poeirinha, e, sobretudo, por Zeca Zonzo são marcas do ideário das sociedades tradicionais africanas, em que o sentimento vivenciado pelo irmão não é o da ruptura abrupta e inexplicável, mas processual, compreensível e desejável, uma vez que essas organizações sociais pensam a salvação como algo coletivo e esse modo de tratar a vivência da morte foi combatido pela igreja cristã-ocidental cuja intenção era deter o poder sobre a salvação, como afirma Baudrillard:

Ao longo de toda a sua trajetória, foi necessário à igreja desmantelar a comunidade primitiva, por ter esta a tendência a tornar a salvação toda sua, recorrendo à sua própria energia, na intensa reciprocidade que a perpassa. Contra a universalidade abstrata de Deus e da Igreja, seitas e comunidades praticam a "autogestão" da salvação, que consiste então na exaltação simbólica do grupo. (BAUDRILLARD, 1996, p. 196)

Zeca parece compreender que é chegada a hora da irmã e que a morte está interligada à vida e que o grupo tem o papel de realizá-la. Ele não somente aceita esse momento como também a auxilia a atravessar esse limite cósmico; tal travessia é retratada simbolicamente como o beijo do mar. O personagem mostra-se, portanto, consciente da infinitude, conferindo ao instante da morte o poder de existir como parte constituinte da vida. 
A gaivota branca que se ergue do corpo de Poeirinha conjuga-se bem com a ideia de liberdade, da transformação e da não extenuação perpétua do ser, mas de sua retirada do plano físico cuja presença se faz ainda perene e é reiterada na última fala do irmão.

Outro elemento importante, inclusive como uma possibilidade de demonstração da interpenetração entre o saber primitivo e contemporâneo é a presença da palavra MAR em registro escrito, mas que não é lida e sim vivenciada através dos dedos de Poeirinha e Zeca ao sublinharem as letras. É unindo uma atitude afetiva do ser humano, o beijo, com a força de um elemento da natureza, o mar, trazido à realidade por meio da palavra vivenciada que o texto forja o valor cíclico da natureza para as sociedades tradicionais africanas, que pressupõe uma simbiose através da qual ocorre a interligação do mundo dos vivos com o mundo dos mortos. Kabenguele Munanga expõe os modos como essas forças trabalham:

O mundo é um conjunto de forças hierarquizadas: deuses, ancestrais, mortos da família, chefes, pais etc. Até as crianças. Através dessas categorias circula uma energia vital, na direção dos deuses, passando pelos ancestrais que são intermediários entre os vivos e os mortos até chegar aos mais jovens, comum dos mortais. (MUNANGA, 1986, p. 61)

Levando em conta esse conjunto de forças dinamizador da energia vital, percebemos que, em O beijo da palavrinha, a criança toma o lugar daquele que deveria deter o conhecimento; não há, nesta obra, a presença marcante de um ancião. É mais efetivamente em A Chuva Pasmada (2004) que podemos entrar em contato com a hierarquia e a lógica que a ancestralidade encerra. Trata-se de uma narrativa contada em primeira pessoa pelo membro mais novo de uma família que se encontra desestabilizada. $\mathrm{O}$ acontecimento tropo dos conflitos a serem resolvidos, que requerem reorganização no contexto familiar e social é a chuva que não cai e o rio que seca. Há no plano físico da estória, uma explicação lógica para tal fato, a existência de uma fábrica e a fumaça que expele. Supostamente, a fumaça impediria a chuva de cair, desequilibrando a natureza.

Logo no primeiro capítulo, o narrador diz-se semelhante à chuva: "Diziam que eu era lento no fazer, demorado no pensar. Eu não tinha vocação para fazer coisa alguma. Talvez não tivesse mesmo vocação para ser. Pois ali estava a chuva, essa clamada e reclamada por todos e, afinal, tão pasmadinha como eu" (COUTO, 2004, p. 7). O fato de ser pasmado como a chuva o coloca no mesmo grupo de Maria Poeirinha e Zeca Zonzo, o dos infundados no mundo, como se algum acontecimento no contexto familiar e social precisasse ocorrer para que suas existências fossem legitimadas. Desencadeia-se, com essa leitura interpretativa, a consideração da importância do ritual, como o processo que gera o reconhecimento social de suas existências e a autorização da passagem de uma fase a outra, seja a do mundo visível para o invisível como ocorre com Poeirinha ou a da fase infantil para a fase adulta, por exemplo. 
Porém, nesta narrativa, diferente de O beijo da palavrinha (2006), existem outros personagens interligados ao evento da morte que não é a de uma criança, mas a de um avô, símbolo e intermediário essencial entre os viventes e os não-viventes. Tal morte não ocorrida correlaciona-se a suspensão da chuva e com a secura do rio; e, a interligação desses acontecimentos naturais com os urbanos, pressagia que as relações precisam se transformar para o retorno do equilíbrio; as relações subjetivas entre os familiares e as relações de trabalho que fornecem os recursos a essa família.

A progressiva cobrança da mãe pela conscientização do marido acerca da atenção quase nula dada ao filho, à família e à comunidade como um todo, disfarçada pela cobrança da resolução do problema da chuva pasmada, também é indício da insatisfação da mulher e da necessidade do restabelecimento da harmonia entre o casal. A passagem abaixo evidencia bem as impressões do filho sobre o pai e a relação de trabalho vivenciada nas minas da África do Sul:

(...) Olhei o seu rosto cansado como se encontrasse nele razões da sua atitude, sempre ausente e preguiçosa. Ainda miúdo, meu pai tinha ido para as minas, lá no Johni. Saíra jovem, voltara envelhecido. Os que ficam órfãos vêem os seus pais serem engolidos pelo chão. $O$ fundo da terra roubara de mim o meu pai, sem o levar da vida. Em menino, eu acordava chorando no meio da noite. Minha mãe acudia, pronta:

- Sonhou com ele, meu filho?

Não. Nas minas do ouro meu velho descia tão fundo que os meus sonhos já não chegavam nem à sua lembrança. Meu sonho era outro, mais escuro. Anos depois, meu pai regressou mas permaneceu ausente, como se lhe faltasse algum inferno. E partiu de novo. E regressou. E voltou a partir. (COUTO, 2004, p. 14)

Assim como a escuridão é o que falta na vida dos familiares de Tio Jaime Litorânio, em A chuva pasmada, o que falta para o pai do narrador é o inferno. O imaginário do inferno presente no ideário do narrador aponta para a interpenetração entre a lógica cíclica das trocas na própria vida concernente a concepção existencial da sociedade primitiva e o espaço em que se espia para além da vida, construção da ideologia judaico-cristã. Porém, ao tratar da necessidade de haver o inferno, de uma falta de inferno, o narrador subverte seu valor. Trata-se novamente do processo de adiamento da morte na vida promovido pela igreja e pelo estado cujo instrumento de poder é o capital e o trabalho, que por sua vez desestimula o poder político da estrutura coletiva da sociedade, como já afirmado em capítulo anterior. A alienação do pai é resultante da polarização entre vida e morte, que se dá a partir da transformação do fio circular da vida em um fio retilíneo.

Esse processo rompe com a força da participação coletiva e com a fundamentação da visão política do mundo a partir dos princípios da sociedade negra, que estão, de forma seminal, contidos na construção literária da família da trama em questão. A conhecida obra do Padre Raul Ruiz de Asúa Altuna, Cultura Tradicional Banto (1985), apresenta elementos constituintes da cultura banto e traz, na primeira parte, os fundamen- 
tos do que chama de participação vital. Com a fala de Mia Couto referida anteriormente, a que esclarece a importância da saúde social da família em detrimento da financeira, queremos aprofundar o reconhecimento da transfiguração dessa cultura negra em um cenário de urbanização e modernização da aldeia, processo que não leva em consideração os saberes da cultura local. Altuna toca na questão da participação como princípio chave para a compreensão dos costumes banto e afirma ainda:

Vida, força, existir, são uma idêntica realidade mais atendível, o valor fundamental, ontológico, donde deriva a sabedoria banto, com o qual elabora a totalidade dos raciocínios, motiva os comportamentos, funda a sua religião, desenvolve e justifica a magia, solidariza a sociedade e regula a ética. (ALTUNA, 1985, p. 47)

Escolher como recurso narrativo a suspensão de uma chuva como situação metafórica, significa não só tratar a chuva como um elemento potencial de interação como também instituir a paralisação dessa chuva como o grande conflito do enredo, o que se conjuga com a perspectiva banto estudada por Altuna. Para esta, a existência dos seres e sua participação social se relacionam diretamente com a importância do movimento, com a força vital resultante da harmonia das interações entre os seres de toda a ordem. Por isso, o estado inerte é algo que ameaça mais do que a morte, porque a morte é considerada como um acontecimento eminentemente transformador, tal qual o é o nascimento. O dinamismo, portanto, é uma qualidade inerente a essa filosofia:

As filosofias conhecidas da África tradicional, possuem em comum ser dinamistas. Representam o mundo não como uma entidade estável, fixa no ser, mas como um devir em perpétuo crescimento... Participando da mesma vida, todos os seres, inclusive o homem, sentem uma profunda fraternidade. Nesta perspectiva, o homem não se situa no mundo afirmando-se, como o ocidental, frente ao que não é ele mesmo nem suas obras, mas sim, sentindo-se como uma parte da natureza, em continuidade com ela. (ALTUNA, 1985, p. 52-53)

Levando em conta que o ancião, na narrativa, é uma possível fonte de sabedoria, principalmente por representar parte importante da corrente que deve fluir através dos personagens pelas gerações posteriores, sua morte está nas engrenagens do movimento gerador do estabelecimento da relação seu neto/narrador e o pai. $\mathrm{O}$ avô perenizado em sua transformação mostra que não há fragmentação entre mundo dos vivos e mundo dos mortos. Ao morrer, se transforma em um rio e, possivelmente, ocupa o papel de ancestral, de um "arquipatriarca" tal qual afirma Altuna: "Estes arquipatriarcas, os primeiros ao qual Deus comunicou a própria força vital e o poder de exercitar sobre toda a sua descendência a influência da energia vital, constituem o elo de união mais elevado que une os homens com Deus" (ALTUNA, 1985, p. 58). 
Durante toda a narrativa, portanto, o avô vai emitindo as pistas para a compreensão dessa chuva que não cai, da relação icônica entre as águas e as mulheres daquela família. Parece que a morte da avó Ntoweni, sua mulher, o coloca em uma posição de espera pela própria partida, uma espera justificada, pois ele encerra em si a possibilidade de harmonização e dinamização da família e da sociedade. Por isso, se recusa a se alimentar e parece estar secando, representando também a imutabilidade em si mesmo, assim como está a chuva pairada no céu.

No entanto, a sabedoria do avô é colocada de forma enviesada. A narrativa de Mia Couto, ao assumir a fusão entre as filosofias negra e ocidental, apresenta o saber do avô também aproximado da loucura, de um pensamento não racional, não lógico, como é o conhecimento de Zeca Zonzo. E é justamente esse pensamento tresloucado que o aproxima do neto - uma criança, que em sua natureza de fronteira, tem a percepção permeável, mutável.

O avô falou como sempre: aos gritos. A voz, rouca, inundou os cantos da casa:

- Eu vi, eu vi!

Era o falar altissonante de quem não ouve e receia não ser escutado. Que tinha visto um peixe subindo nos céus, imitando o voo de um pássaro. Os da casa riram-se:o avô e seus delírios. Mas eu gostei de acreditar e, no meu pensamento, já cardumes atravessavam as nuvens, rebrilhando entre a sarapintada claridade. E cheguei mesmo a escutar o bater de barbatanas, o ar assobiando entre as coloridas escamas dos peixes. (COUTO, 2004, p. 24)

O avô parece estar atrofiado da consciência devido à idade, mas, é exatamente dessa forma que ele é exposto como um sábio, mostra a interpenetração entre vida e morte e parece intuir que a pasmaceira da chuva é uma espécie de maldição que simboliza problemas mais internos, relativos à organização familiar, que externos, como afirma na fala: “- Inimigos? Com a idade fui descobrindo que acabamos fazendo coisas bem piores que nossos inimigos" (COUTO, 200, p. 10) Fala que dialoga sobremaneira com a de Mia Couto no discurso de opinião citado no princípio do capítulo, "Fronteira da Cultura", texto em que trata dos fantasmas internos de Moçambique para além dos externos, uma vez que estes, teoricamente, se foram com o fim da colonização. Mia Couto aponta, dessa forma, para uma revisão da relação norte e sul, dominantes e dominados, através da exposição do fato de que sempre houve elites internas coniventes com a dominação e que estas não cessaram de existir no pós-independência.

Essa visão problematizada das formas de lidar com os acontecimentos provenientes da estrutura do pensamento que se ancora na cultura negra se dá também através da tensão entre perspectivas religiosas, evidenciadas a partir do olhar de outra personagem, a tia. A ansiedade dessa personagem que parece se encontrar mais na expectativa de transformação que as outras, entende o encadeamento dos fatos através da relação de causa e 
efeito motivada pela culpa. Imbuída, mais pelos preceitos da ideologia cristã do que pelos advindos da religiosidade da cultura ancestral expõe uma percepção maniqueísta da vida e acredita que alguém poderá ser punido. Suas concepções são conflitantes com as do avô, o que colabora também com a crise existencial do narrador como quando ouve os seguintes conselhos da tia: "Eu que não emprestasse ouvido aos restantes, crédulos em espíritos e mezinhas. Que isso não era de civilizado. Sobretudo, eu não desse crédito ao avô, ele era o mais dado aos ancestrais" (COUTO, 2006, p. 19).

A postura da tia exibe também a situação de fronteira cultural em que vivem os personagens da trama. A partir do modo como é lida uma oração ou da forma como são vistos os modos de rezar, percebemos que a forma cristã de religiosidade é parte de um complexo em que os elementos de outra religiosidade são levados em consideração, ou seja, seus olhares estão deslocados. A saber:

Entretanto, na pequenina igreja, ecoavam as rezas e eu escutava perfeitamente a voz da tia: - Pai nosso, cristais no Céu, santo e ficado seja o vosso nome. (COUTO, 2006, p. 19).

Seguiram-se cantos e rezas, rezas e cantos. Lembrei as palavras do avô: não são os cristãos que se fatigam, Deus é que não tem fôlego para tanta oração. (COUTO, 2006, p. 19).

Tal conflito é perene na constituição psicológica do narrador, uma vez que motivado pelas contradições ideológicas dos familiares se percebe também como um ser que pode ou não colaborar para a reorganização de seu mundo, o que se dá através do entendimento da morte como um elemento de equilíbrio social, como parte do movimento de interação entre os seres, mas também da visão religiosa da vida para além dos parâmetros cristãos herdados da religião hegemônica. A compreensão da presença do invisível na vida ordinária como elemento potencialmente influente é o que subverte a ordem retilínea de sua vida e de seus familiares que em dado momento paralisa a circularidade. Nessa perspectiva, religião e magia se assemelham e são inerentes à realidade física. Altuna esclarece:

A magia e a actividade religiosa não intentam outra coisa senão controlar ou desviar a inter-acção. O banto admite uma relação invisível que o rodeia. Aqui enraíza a sua religiosidade, porque se submete a esta realidade que o supera. Ali se joga a sua felicidade ou desgraça, se forja o seu destino, a certeza de que a sua vida está envolta em forças misteriosas e eficazes, provoca toda a actividade mágica, os mecanismos de ataque e defesa que perturbam a harmonia sonhada e desejada pela pessoa e pela sociedade. (ALTUNA, 1985, p. 62)

Retornamos assim aos estudos de Muniz Sodré sobre a cultura negra e colocamos em diálogo o que esclarece acerca do fato de não ser importante para essa cultura o esclarecimento da verdade como o é para a cultura ocidental. O objetivo do ritual, portanto, não é o esclarecimento do enigma, mas a garantia da produção de energia vital, do movimento. $\mathrm{O}$ 
ritual de passagem porque passa o narrador é impulsionado pela relação com o avô, e, esse relacionamento estreito exibe a intenção do mais velho de iniciar o desenvolvimento do mais novo quanto à sua capacidade de se reconhecer parte da união vital em que está inserido, em um processo de aceitação e da recepção familiar e social junto da responsabilização de manter o movimento. É através do despertar do neto, que o avô acaba por atingir o filho, estabelecendo o elo entre as três gerações. Subjaz, assim, no desequilíbrio familiar a necessidade da manutenção da relação com o mundo dos mortos, da reinserção da morte como força motriz do movimento, do entendimento da participação coletiva para que a vida ganhe substância, forma e sentido. Novamente, em palavras de Altuna:

Em qualquer comunidade banto entende-se por participação ou união vital "uma relação de ser e de vida de cada um com os seus descendentes, sua família, seus irmãos e irmãs de clã, sua ascendência, e com Deus.

Em segundo lugar "uma relação ôntica, análoga de cada um com o seu patrimônio, o seu haver, com tudo aquilo que contém ou produz, com tudo aquilo que ali cresce e vive".

A vida une - solidariza os vivos entre si e estes com os seus antepassados, porque todos se encontram, comungam de uma idêntica realidade constitutiva, embora diversamente dosificada. (ALTUNA, 1985, p. 54)

A lenda das Ntowenis conta a estória da bisavó do narrador, que, em momento de seca vivido pela família e aldeia em que vivem, parte em busca de água, e quando a consegue e retorna, acaba morrendo. A cabaça cheia de água que cai e se quebra no chão quando a ancestral morre, funda o rio que abastece a família e a aldeia. Percebemos, portanto, que o rio, a água e o mar trazem o fio condutor do diálogo entre vida e morte, nesse sentido, vida resulta como fim da estagnação do fluxo subjetivo entre os familiares.

Podemos interpretar que a narrativa é uma reedição desta lenda: novamente não há água na aldeia. $\mathrm{O}$ avô é quem detém as respostas para resolver a questão da chuva interrompida e da secura do rio. Em vários momentos, ele emite indícios sobre a sua própria partida, colocando em prática seu papel na família.

Os comentários pontuais do avô, no mais das vezes, metaforizam as relações entre os familiares, costurando e alimentando os diversos membros da família que deve ocorrer como fluxo de água, o meio pelo qual as transformações ocorrerão. À medida em que as situações entre os familiares vão se resolvendo, o avô parece atravessar as etapas da aceitação de que é chegada a sua hora. Em dado momento, quando chora de saudade, tal incômodo é suavizado por meio do contato com um búzio. Com o búzio no colo o avô acaba por se acalmar, sinalizando que a aceitação e necessidade de sua transmutação e, novamente, assim como os personagens em $O$ beijo da palavrinha (2006), o mar é a imensidão na qual os seres se dissolvem 
sem se acabarem e o búzio, um índice dessa infinitude. É, importante, nesse ponto, esclarecer, que para o avô se transformar em rio, significa chegar ao mar e que o mar é sua mulher, Ntoweni.

Podemos perceber que a despedida do avô é uma regra do jogo desse ritual: a troca biossimbólica se coaduna com toda a trajetória das Ntowenis, cujo valor ancestral é a permissão para que tudo funcione e se harmonize na família. O desejo do rio seco é a morte do avô, assim como é desejo de Ntoweni, sua esposa, que se transfigura em mar.

A estória se complica no momento em que o pai do narrador descobre que a mãe vai encontrar o dono da fábrica em que trabalha na tentativa de angariar respostar para resolver o problema. Esse ponto de tensão entre os pais resulta numa luta que gera o entendimento conjugal. Restabelecido o equilíbrio entre homem e mulher, a trama caminha para o fim do processo ritualístico, em que o avô morre. Enquanto os dois, neto e filho, empurram o barco do avô para a outra ponta do rio onde está o mar que é também Ntoweni, ocorre a interação entre o rio seco e a chuva pasmada, bem como entre o pai e o filho, à luz da seguinte fala: “- Não fique triste, filho. Que tudo isso é um engano. Não é o morrer que é para sempre. O nascer é que é para sempre." (COUTO, 2004, p. 70) e sendo remo do próprio barco, o avô é direcionado ao mar.

Ainda segundo Baudrillard, é a iniciação, na ordem primitiva, o tempo de uma operação simbólica que visa a articular a morte socialmente, transformando-a em contexto de troca entre os ancestrais e os vivos, em que não há separação, mas circulação:

Está claro que a iniciação consiste na instauração de uma troca onde só havia fato bruto: da morte natural, aleatória e irreversível, passa-se a uma morte dada e recebida, logo, reversível na troca social, "solúvel" na troca. Nesse mesmo movimento, a oposição entre o nascimento e a morte desaparecem: eles também podem trocar-se sob as espécies da reversibilidade simbólica. A iniciação é um momento crucial, o nexo social, a câmara escura na qual nascimento e morte, deixando de ser os termos da vida, reinvoluem um no outro não rumo a alguma fusão mística, antes para fazer do iniciado um verdadeiro ser social. (BAUDRILLARD, 1996, p. 180)

É a partir do ritual de passagem do avô, que o narrador restabelece o elo com o pai e pode realizar o seu processo de iniciação. Deixando a negação social, o pai autoriza o amadurecimento do filho por meio da atitude simbólica de lançar sobre ele o primeiro jorro de água que brota da terra. Enquanto toda a família, em dança, se aproxima, o rio refaz suas margens. O pai, imbuído de nova força vital, toma a parte que lhe cabe no fio entre os ancestrais e os seres viventes, compreendendo, inclusive que estar vivo é permitir-se viver no outro, no caso, em seu filho. Ele assume o papel de mais velho da família, o avô do possível filho de seu filho. 
O menino, que observou a canoa do avô sumindo no horizonte como a cabaça tombada das mãos da primeira Ntoweni, agora em tom de compreensão, mostra ter percebido o desejo do avô:

Assim se cumpre, sem mesmo eu saber, a intenção de meu velho avô: ele queria o rio sobrando da terra, vogando em nosso peito, trazendo diante de nós as nossas vidas de antes de nós. Um rio assim, feito só para existir, sem outra finalidade que riachar, sagradeando o nosso lugar.

Como ele sempre dissera: o rio e o coração, o que os une? $\mathrm{O}$ rio nunca está feito,como não está o coração. Ambos são sempre nascentes, sempre nascendo. Ou como eu hoje escrevo milagre é o rio não findar mais. Milagre é o coração começar sempre no peito de outra vida. (COUTO, 2006, p.74)

Com a união dos dois semas de ordens diferentes: rio e coração, o narrador desenvolve a compreensão das forças de participação e de movimento latentes na dimensão religiosa de outra concepção diferente da eurocêntrica. A resolução mágica, recurso literário, que encerra a narrativa, uma vez que não há explicação científica nem para a chuva se pasmar e nem para os motivos que a fizeram cair, colabora com o ponto inicial das análises literárias empreendidas. A saber, escolher como recurso narratológico a valorização das trocas simbólicas à luz da aleatoriedade mística da vida, como uma religiosidade que regula inclusive a ética social é uma forma de estimular pensar também a dimensão mágica do posicionamento político das sociedades locais contemporâneas em Moçambique, retomando o artigo de Maria Paula Meneses acerca das teias complexas do conhecimento que envolvem linguagens de resistência e corpos de violência citado no início do capítulo.

Meneses paraleliza instabilidades provocadas pela feitiçaria que antes afetavam a harmonia social no tempo e espaço pré-modernos às instabilidades agora de ordem econômica que marginalizam comunidades locais em Moçambique na contemporaneidade. Os portadores do mal da atualidade são aqueles que detêm o poder para subjugar os destinos dos mais desprovidos e acabam por ser atacados, nesse caso, com as denúncias de tráfico de órgãos destinados à feitiçaria:

A propagação dos boatos e acusações estabelece os desejos almejados pela comunidade, expondo as relações de poder presentes. Numa escala mais ampla, pode definir o relacionamento da comunidade com o do Estado moçambicano, considerado injusto, e, por isso, como devendo ser desafiado. (MENESES, 2010, p. 250)

Deste modo, os tratamentos dados à morte a partir da valorização dos saberes locais estruturados em trocas simbólicas, valorização que é evidenciada pelo olhar da infância como lugar de deslocamento, aprendizagens e descobertas e, por fim, a solução narratológica que elege a magia como forma de resolução dos conflitos, visando ao estabelecimento do movimento da força vital e da conscientização do valor da morte como reversibilidade simbólica e processo ritualístico, fazem das obras literárias 
coutianas exemplos de discussões complexas da construção dos posicionamentos dos povos que compõem a nação moçambicana e da reivindicação da responsabilidade moral do Estado em garantir a regulação política das várias consciências cívicas provenientes dessas culturas locais através da sua compreensão e consideração.

Retornemos ao artigo de Walter Mignolo para pensar o salto que o mesmo propõe a partir de um radicalismo das teorias pós-coloniais. Ao colocar a diferença do empoderamento político do Estado-nação (como o representante de uma parte da população) e o empoderamento político da população, Mignolo faz a distinção entre política de identidade e identidade em política e, portanto, passa a tratar do assunto da construção da identidade a partir do que chama de interculturalidade. A saber,

\begin{abstract}
a interculturalidade deve ser entendida no contexto do pensamento e dos projetos descoloniais. Ao contrário do multiculturalismo, que foi uma invenção do Estado-nacional nos EUA para conceber "cultura" enquanto mantém "epistemologia", inter-culturalidade nos Andes é um conceito introduzido por intelectuais indígenas para reivindicar direitos epistêmicos. A inter-cultura, na verdade, significa inter-epistemologia, um diálogo intenso que é o diálogo do futuro entre cosmologia não ocidental (aymara, afros, árabes-islâmicos, híndi, bambara, etc.) e ocidental (grego, latim, italiano, espanhol, alemão, português). (MIGNOLO, 2008, p. 316)
\end{abstract}

Queremos, assim, com base nesse entendimento inter-epistemológico, observar os elementos literários de cada obra, que compõem esses espaços de trânsito e deslocamento, confrontados, para pensá-los em um movimento heterogêneo e pluralístico. Nesse sentido, tratamos dos motivos pelos quais "morte" e "infância" a partir dos modos como são discutidos e inter-relacionados nas obras podem ser vistos como opções de/para descolonização epistemológica, modos que permitem transitar elementos dos dois grupos de cosmologias acima citados por Mignolo.

Queremos, sobretudo, relembrar o papel de veiculação de concepções ideológicas, filosóficas e políticas que o livro infantojuvenil, desde os primórdios da institucionalização da educação infantil, enquanto ferramenta formadora dessa classe carrega. São bases culturais e epistêmicas que norteiam as escolhas de títulos empreendidas pelas escolas e pelas famílias (pelos adultos), instituições que, em sua maioria, tomam como base o processo educativo e civilizatório também imposto pela colonialidade em escala global, de forma a nivelar e homogeneizar através de uma formação que determina o controle das ações e atitudes políticas dos indivíduos. Assim como afirma Manuel Jacinto Sarmento em "As culturas da infância nas encruzilhadas da $2^{a}$ modernidade" (2002):

...importa sublinhar que esse esforço normalizador e homogeneizador, se tem efectivas consequências na criação de uma infância global (Sarmento, 2001b), não anula - antes potencia - desigualdades inerentes à condição social, ao gê- 
nero, à etnia, ao local de nascimento e residência e ao subgrupo etário a que cada criança pertence. Há várias infâncias dentro da infância global, e a desigualdade é o outro lado da condição social da infância contemporânea. Aliás, esta radicalização da modernidade - esta $2^{\text {a }}$ modernidade (U. Beck, 1999) - acentua essas desigualdades, no quadro do efeito homogeneizador do processo de globalização. É, por isso, necessário, considerar esses efeitos. (SARMENTO, 2002, p. 6)

Com base em uma reflexão acerca desses efeitos ditos na citação acima, tratamos o olhar infantil utilizado para equacionar os acontecimentos das narrativas a partir do entre-lugar, ou seja, do lugar de fronteira, que, como afirma Homi Bhabha "fornecem o terreno para a elaboração de estratégias de subjetivação - singular ou coletiva - que dão início a novos signos de identidade e postos inovadores de colaboração e contestação, no ato de definir a própria ideia de sociedade" (BHABHA,2013, p. 20). A infância e seu olhar representados literariamente nos remetem, portanto, a um lugar deslocado daquele de onde vêm os paradigmas sociais normalizadores e homogeneizadores. Representar a fala infantil, imbuída dessa reflexão, é deslocar o pensamento do eixo paradigmático, portanto, é de orientação descolonial.

\title{
REFERÊNCIAS BIBLIOGRÁFICAS
}

\author{
Obras Literárias:
}

COUTO, Mia. A Chuva Pasmada. Lisboa: Editorial Caminho, 2004. O beijo da palavrinha. Rio de Janeiro: Língua Geral, 2006.

\section{Obras Teóricas:}

ALTUNA, Raúl Ruiz de Asúa. Cultura tradicional banto. Luanda: Secretariado Arquidiocesano de Pastoral, 1985.

ARAÚJO, Maria Paula; SEPÚlVEDA, Myrian. História, memória e esquecimento: implicações políticas. Revista Crítica de Ciências Sociais, Coimbra, n. 79, 2007.

BALLESTRIN, Luciana. América latina e o giro decolonial. 2013. Disponível em: http://www.scielo.br/scielo.php?pid=S0103-33522013000200004\&script=sci_arttext Acesso em: 10 fev. 2015.

BAUDRILLARD, Jean. A troca simbólica e a morte. São Paulo: Edições Loyola, 1996.

BAUMAN, Zigmunt. Medo Líquido. Rio de Janeiro: Jorge Zahar, 2008.

BHABHA, Homi. O local da cultura. Belo Horizonte: Editora UFMG, 2013 
CABAÇO, José Luís. Moçambique: identidade, colonialismo e libertação. São Paulo: Editora UNESP, 2009.

COUTO, Mia. "O gato e o novelo". Entrevista a José E. Agualusa. In: JL. Lisboa, 8 out. 1997.

FONSECA, Maria Nazareth Soares\& CURY, Maria Zilda Ferreira. Mia Couto: Espaços Ficcionais. Belo Horizonte: Autêntica Editora, 2008..

GROSFOGUEL, Ramón. "Para descoloniza os estudos de esconomia política e os estudos pós-coloniais: transmodernidade, pensamento de fronteira e colonialidade global. In. SANTOS, Boaventura de Sousa \& MENESES, Maria Paula (Org.). Epistemologias do Sul. São Paulo: Cortez, 2010.

HALL, Stuart. Da diáspora: identidades e mediações culturais. Belo Horizonte: UFMG, 2013.

HUNT, Peter. Crítica, Teoria e Literatura Infantil.São Paulo: Cosac Naify, 2010.

LÓPEZ, Maximiliano Valerio. "Infância e colonialidade" In. VASCONCELLOS, Tânia de. (Org.) Reflexões sobre infância e cultura. Niterói: EdUFF, 2008.

MENESES, Maria Paula. "Corpos de violência, linguagens de resistência: as complexas teias de conhecimento no Moçambique contemporâneo". In.__ SANTOS, Boaventura de Sousa\& MENESES, Maria Paula (Org.). Epistemologias do Sul. São Paulo: Cortez, 2010.

MIGNOLO, Walter. Desobediência Epistêmica: A opção descolonial e o significado de identidade em política. 2008. Disponível em: http://www.uff. br/cadernosdeletrasuff/34/traducao.pdf Acesso em: 21 jan. 2015.

MUNANGA, Kabengele. Negritude: usos e sentidos. São Paulo: Ática, 1986.

NOA, Francisco. Império, mito e miopia: Moçambique como invenção literária. Lisboa: Caminho, 2002.

PADILHA, Laura Cavalcante. Entre voz e letra: o lugar da ancestralidade na ficção angolana do século XX. Niterói: EDUFF, 1995.

RAMOSE, Mogobe B., "Globalização e Ubuntu”. In. SANTOS, Boaventura de Sousa \& MENESES, Maria Paula (Org.). Epistemologias do Sul. São Paulo: Cortez, 2010.

. Sobre a Legitimidade e o Estudo da Filosofia Africana. 2011. Disponível em: http://www.ensaiosfilosoficos.com.br/Artigos/Artigo4/ RAMOSE_MB.pdf Acesso em: 10 fev. 2015.

RODRIGUES, José Carlos. Tabu da morte. $2^{\mathrm{a}}$ ed. Rio de Janeiro: Editora Fiocruz, 2006. 
SANCHES, Manuela Ribeiro. (Org). Malhas que os impérios tecem. Lisboa: Edições 70, 2011).

SANTIAGO, Silviano. Uma literatura nos trópicos. $2^{\text {a }}$ ed. Rio de Janeiro: Rocco, 2000.

SANTOS, Boaventura de Sousa \& MENESES, Maria Paula (Org.). Epistemologias do Sul. São Paulo: Cortez, 2010.

SARMENTO, Manuel Jacinto. As culturas da infância nas encruzilhadas da $2^{a}$ modernidade. 2002. Disponível em: http://cedic.iec.uminho.pt/ Textos_de_Trabalho/textos/encruzilhadas.pdf Acesso em: 21 jan. 2015.

. "O beijo da palavrinha de Mia Couto: uma estória em perigo”. In:_Entre fábulas e alegorias: ensaios sobre literatura infantil de Angola e Moçambique. Rio de Janeiro: Quartet: UFRJ: Centro de Letras e Artes, 2007.

Travessias e margens da existência: representações da morte em textos literários de Angola e Moçambique. Revista Navegações. UFRJ. Jan/jun. 2012.Disponível em: http://revistaseletronicas.pucrs.br/ojs/index. php/navegacoes/article/viewFile/11075/7600

SODRÉ, Muniz. A verdade seduzida. Rio de Janeiro: DP\&A, 2005.

VASCONCELLOS, Tânia de. (Org.) Reflexões sobre infância e cultura. Niterói: EdUFF, 2008.

Recebido para publicação em 12/09/2016

Aprovado em 07/11/2016

\section{NOTAS}

1 Especialista em Literatura Infantil e Juvenil pela UFRJ e Mestre em Literatura Portuguesa e Literaturas Africanas de Língua Portuguesa pela UFF.

2 HEGEL apud LEITE, 2008: 20.

3 Não estamos nos referindo à religião cristã como um todo, mas a objetivos ligados a uma determinada interpretação dessa religião. 